Jurdimas (Jurnal Pengabdian Kepada Masyarakat) Royal

Vol. 5 No. 1, Januari 2022, hlm. 105 - 110

Available online at https:/jurnal.stmikroyal.ac.id/index.php/jurdimas

\title{
PENGEMBANGAN UMKM MELALUI PELATIHAN PEMBUKUAN SEDERHANA DAN PENGENDALIAN INTERN DI DESA SOREANG
}

\author{
Irmah Halimah Bachtiar ${ }^{1 *}$, Ramli Toalib ${ }^{1}$, Nursyam Ar ${ }^{1}$, Andi Musfirawati Nur ${ }^{2}$ \\ ${ }^{1}$ Akuntansi, Universitas Indonesia Timur \\ ${ }^{2}$ Manajemen, Universitas Indonesia Timur \\ email:*irmahalimah@gmail.com
}

\begin{abstract}
Micro, Small and Medium Enterprises (MSMEs) have an important role in economic recovery in Indonesia. The development of MSMEs cannot be separated from the ability of MSME owners to manage and record their finances. The bookkeeping carried out by the company needs to be supported by the implementation of an adequate Internal Control System to support the achievement of company goals. Therefore, MSMEs need to implement internal control that can be used as a tool to prevent or overcome fraud and protect company resources. This activity aims to provide education to the Soreang village community, the MSME group regarding simple bookkeeping and internal control which will be able to improve skills and knowledge in designing future business strategies, managing finances and protecting company assets. This activity is carried out through providing socialization first and then providing training to participants on the concepts and practices of simple bookkeeping and the application of internal control. The results of the service are village communities consisting of PKK women and Healthy Community Movement who are members of the MSME group activities understand and feel motivated by the additional knowledge about simple bookkeeping and internal control systems, and Participants feel that this training is very useful for developing MSMEs in the context of community empowerment in Seroang Village
\end{abstract}

Keywords: MSMEs; simple bookkeeping; internal control

Abstrak: Usaha Mikro, Kecil dan Menengah (UMKM) memiliki peran penting dalam pemulihan perekonomian di Indonesia. Berkembangnya UMKM tidak terlepas dari kemampuan pemilik UMKM dalam mengelola dan membukukan keuangannya. Pembukuan yang dilakukan perusahaan perlu didukung dengan adanya penerapan Sistem Pengendalian Intern yang memadai demi menunjang pencapaian tujuan perusahaan. Oleh karena itu, UMKM perlu menerapkan pengendalian intern yang bisa dijadikan alat untuk mencegah atau mengatasi fraud (kecurangan) dan melindungi sumber daya perusahaan. Kegiatan ini bertujuan untuk memberikan edukasi kepada masyarakat desa Soreang kelompok UMKM mengenai pembukuan sederhana dan pengendalian intern yang nantinya mampu meningkatkan keterampilan serta pengetahuan dalam merancang strategi bisnis kedepannya, mengelola keuangan dan melindungi aset perusahaan. Kegiatan ini dilaksanakan melalui pemberian sosialisasi terlebih dahulu kemudian memberikan pelatihan kepada peserta mengenai konsep serta praktik pembukuan sederhana dan penerapan pengendalian intern. Hasil pengabdian yaitu masyarakat desa yang terdiri ibu-ibu PKK dan Germas (Gerakan Masyarakat Sehat) yang tergabung dalam kelompok UMKM mengerti dan merasa termotivasi dengan adanya tambahan pengetahuan mengenai pembukuan sederhana dan pengendalian intern. serta peserta merasa pelatihan ini sangat bermanfaat untuk mengembangkan UMKM dalam rangka pemberdayaan masyarakat di Desa Seroang

Kata kunci: UMKM; pembukuan sederhana; pengendalian intern

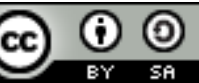


Jurdimas (Jurnal Pengabdian Kepada Masyarakat) Royal

Vol. 5 No. 1, Januari 2022, hlm. 105 - 110

ISSN 2614-7912 (Print)

DOI: https://doi.org/10.33330/jurdimas.v5i1.1264

ISSN 2622-3813 (Online)

Available online at https:/jurnal.stmikroyal.ac.id/index.php/jurdimas

\section{PENDAHULUAN}

Seluruh Usaha Mikro, Kecil dan Menengah (UMKM) mempunyai peran penting dalam pemulihan perekonomian di Indonesia. Adanya komitmen pemerintah untuk terus mendukung UMKM sehingga nantinya bisa tetap bertahan serta mampu berkembang di tengah pandemi yang tak kunjung usai. Berdasarkan data Kementrian Koperasi dan Usaha Kecil dan Menegah (KemenkopUKM) pada bulan Maret 2021, jumlah UMKM mencapai 64,2 juta dengan kontribusi terhadap Produk Domestik Bruto sebesar 61,07 persen atau senilai $\mathrm{Rp} 8.5573,89$ triliun. Dari total tenaga kerja yang ada, maka terdapat 97 persen mampu diserap oleh UMKM, serta dapat menghimpun sampai 60,42 persen total investasi yang ada di Indonesia (Kemenkeu, 2021).

Berkembangnya UMKM tidak terlepas dari kemampuan pemilik UMKM dalam mengelola dan membukukan keuangannya, sehingga hal ini tak jarang justru menjadi masalah krusial yang sering ditemukan pada UMKM di Indonesia. Banyaknya masalah keuangan disebabkan karena minimnya kemampuan pemilik UMKM dalam mengelola serta membukukan keuangan usaha, adanya pemasukan maupun pengeluaran yang tidak tercatat dengan jelas dan rapi.

Pembukuan sederhana merupakan suatu istilah yang sudah umum bagi para pengusaha termasuk pelaku UMKM. Apapun jenis usaha atau bisnis, baik itu usaha atau bisnis yang berskala kecil hingga berskala besar sangat penting untuk memahami penyusunan pembukuan keuangan, yaitu pembukuan sederhana. Pembukuan sederhana tentunya tidak terlepas dari laporan keuangan. Laporan keuangan adalah laporan yang berisi tentang informasi keuangan suatu perusahaan sekaligus menggambarkan kinerja perusahaan tersebut dalam suatu periode (Bachtiar \& Nurfadila, 2019), seperti laporan neraca, laporan perubahan ekuitas, laporan laba rugi, laporan arus kas, dan laporan lainnya.

Perkembangan bisnis UMKM sangat dipengaruhi oleh pencatatan sederhana. Dengan adanya pembukuan yang dilakukan, maka pemilik UMKM mampu membaca kondisi dan perkembangan bisnis termasuk laba ataupun rugi perusahaan. Oleh karena itu, pembukuan sederhana mampu dijadikan acuan dalam merancang strategi bisnis kedepannya.

UMKM tidak hanya perlu memiliki pembukuan tetapi juga dituntut untuk memiliki sistem Pengendalian Intern yang memadai demi menunjang pencapaian tujuan perusahaan (Wirawan, Djajadikerta, \& Setiawan, 2021). Mekanisme pengendalian intern merupakan salah satu alat yang dapat digunakan untuk memonitor atau mengontrol sumber daya manusia pada UMKM. Pada zaman sekarang ini, pengendalian intern dianggap sebagai cara untuk mencegah dan mendeteksi fraud (kecurangan) dan melindungi sumber daya fisik maupun intangible yang pada akhirnya akan menghasilkan efisiensi dan berfungsinya bisnis dengan baik (Cika, 2007).

Pada masa seperti saat ini, usaha kecil menengah sudah tidak dapat dikelola hanya dengan mengandalkan kemampuan manajemen tradisional. Hal ini yang menyebabkan sejumlah UMKM kalah bersaing dengan perusahaan besar. Pemicu utama sehingga banyaknya UMKM yang tidak mampu bersaing bahkan ditutup adalah karena kesalahan pengelolaan usaha pada UMKM. Adanya ketidakmampuan mengelola risiko, menjaga harta perusahaan dan sumber daya lainnya menjadi kelemahan pada UMKM. 
Available online at https://jurnal.stmikroyal.ac.id/index.php/jurdimas

Pada umumnya pemilik UMKM akan merekrut tenaga kerja ketika usaha semakin berkembang, sehingga hal ini yang menjadi peluang akan munculnya masalah baru dalam perusahaan dibandingkan jika usaha masih dikelola sendiri oleh pemilik. Perusahaan yang termasuk ke dalam kategori berskala kecil cenderung menghadapi masalah kekurangan sumber sehingga hal tersebut menjadi kelemahan pengendalian intern yang signifikan. Oleh karena itu, UMKM perlu menerapkan pengendalian intern yang bisa dijadikan alat untuk mencegah atau mengatasi kelemahan tersebut.

Berdasarkan hasil survei yang dilaksanakan oleh tim pengabdian kepada masyarakat sebelum melakukan kegiatan pelatihan ini yaitu belum adanya pembukuan yang rapi sesuai dengan proses pencatatan keuangan akuntansi sederhana. Hasil wawancara yang telah dilakukan sebelumnya, disimpulkan bahwa pada umumnya kelompok UMKM belum melakukan pencatatan secara benar berdasarkan prinsip dasar akuntansi. Bahkan tidak banyak dari masyarakat yang bisa membedakan antara modal dan keuntungan atau laba. Dari hasil wawancara tersebut, mereka terkadang mencampur modal usaha dan keuntungan hasil usaha yang didapatkan dari penjualan produk UMKM. Hal inilah yang sering menjadi masalah krusial dalam mengelola keuangan perusahaan.

Melihat permasalahan tersebut, maka kami dari tim pengabdian masyarakat yang memiliki latar belakang dari Ilmu Ekonomi yaitu Akuntansi, ingin memberikan edukasi dan tambahan pengetahuan melalui pelatihan pembukuan sederhana dan pengendalian intern yang nantinya mampu menjadi solusi dalam mencegah atau meminimalisir terjadinya kecurangan dalam perusahaan serta membantu UMKM untuk mengelola keuangan dengan baik.

Berdasarkan latar belakang yang diuraikan, sehingga kami memandang penting untuk melakukan kegiatan Pengabdian Kepada Masyarakat dengan pemberian Pelatihan Pembukuan Sederhana dan Pengendalian Intern Pada UMKM di desa Soreang yang sudah memiliki produk yang masih langka, yaitu keripik tude.

Tujuan dilaksanakannya program pengabdian masyarakat adalah memberikan edukasi berupa sosialisasi dan pelatihan kepada peserta PKM khususnya masyarakat desa Seroang yang terdiri dari kelompok ibu-ibu PKK dan Germas yang tergabung dalam kelompok UMKM mengenai pembukuan sederhana dan pengendalian intern yang bisa dijadikan patokan dalam merancang strategi bisnis kedepannya, melindungi aset perusahaan serta pemilik UMKM dapat melihat keadaan dan perkembangan bisnis termasuk laba maupun rugi yang diperoleh perusahaan. Kegiatan pelatihan pembukuan sederhana UMKM ini juga merupakan salah satu bentuk program pemerintah yang mengharapkan UMKM naik kelas (Sari \& Indriani, 2017).

\section{METODE}

Kegiatan PKM ini dilaksanakan di kantor desa Soreang kecamatan Mappakasunggu kabupaten Takalar Sulawesi Selatan, kegiatan berlangsung selama satu hari. Peserta PKM (Partisipan) merupakan ibu-ibu PKK dan Germas (Gerakan Masyarakat Sehat) yang tergabung dalam kelompok UMKM sebanyak 29 orang. Metode yang digunakan yaitu pelatihan yang sebelumnya dibuka dengan ceramah atau pemaparan materi, kemudian diskusi dan 
tanya jawab serta diakhiri dengan praktek dalam menyusun laporan keuangan. Kegiatan pengabdian ini dikoordinasikan terlebih dahulu kepada Kepala Desa terkait dengan pelaksanaan dan sasaran masyarakat wilayah setempat. Peserta yang menjadi partisipan PKM adalah kelompok UMKM yang terdiri dari ibu-ibu PKK dan Germas (Gerakan Masyarakat Sehat) yang ada di desa Soreang Kabupaten Takalar.

Pelaksanaan pada awalnya yaitu peserta diberikan pemahaman tentang pengembangan UMKM dalam rangka pemberdayaan masyarakat desa. Berikutnya, peserta diberikan penjelasan tentang pembukuan sederhana dan pengendalian intern untuk UMKM agar UMKM tersebut bisa berkembang dan bersaing kedepannya. Kemudian peserta dilatih untuk membuat pembukuan sederhana dengan memberikan beberapa contoh jenis pembukuan yang harus dimiliki oleh UMKM. Peserta juga diberi gambaran pembukuan dengan menggunakan aplikasi.

\section{PEMBAHASAN}

Acara PKM ini dibuka oleh Ketua Program Studi, dan dilanjutkan dengan sepatah kata dari Kepala Desa Soreang. Setelah itu dilakukan pemaparan materi mengenai Pembukuan Sederhana dan Pengendalian Intern pada UMKM. Kegiatan pelatihan dilakukan dalam bentuk presentase menggunakan bantuan infocus untuk menampilkan materi serta narasumber berusaha menjawab pertanyaan-pertanyaan dari para peserta PKM.

Tujuan dari pemberian pelatihan pembukuan sederhana dan Sistem Pengendalian Intern terhadap masyarakat kelompok UMKM Desa Soreang adalah untuk memberikan edukasi mengenai pentingnya proses pembukuan sederhana dan sistem pengendalian intern dalam rangka mengelola suatu usaha. Selain itu kegiatan pengabdian ini bertujuan untuk meningkatkan keterampilan dan pemahaman ipteks masyarakat dalam rangka pemberdayaan masyarakat desa.

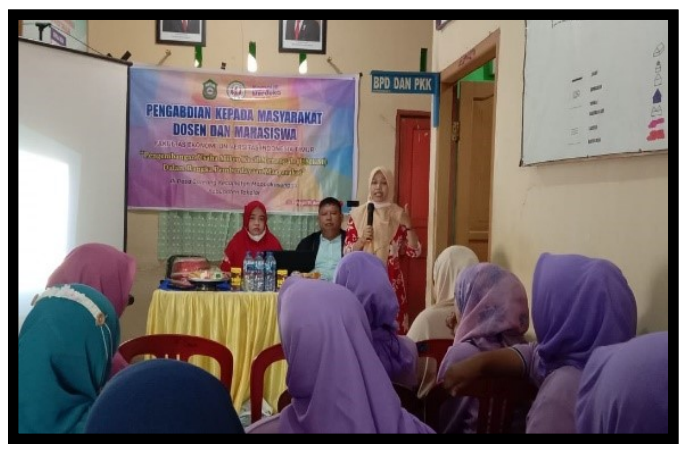

Gambar 1. Pemaparan Materi mengenai Pembukuan Sederhana

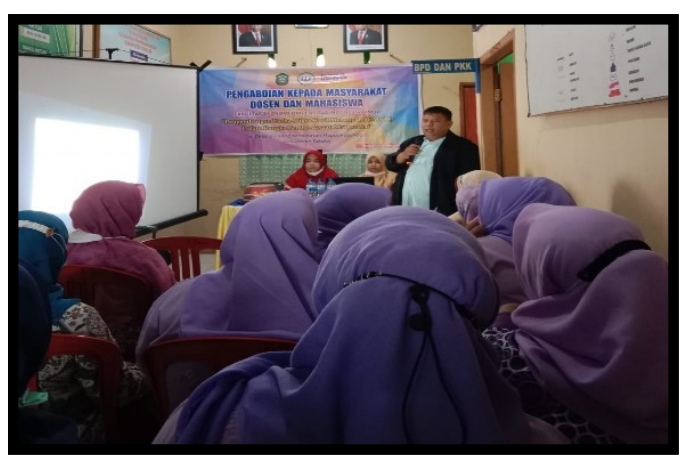

Gambar 2. Pemaparan Materi mengenai Pengendalian Intern

Tim pengabdian kepada masyarakat melihat antusiasme dari peserta yang sangat tinggi untuk mengikuti pelatihan ini. Selama kegiatan berlangsung, banyak di antara peserta yang ingin mengajukan pertanyaan. Berdasarkan hasil tanya jawab, terlihat bahwa masyarakat desa Soreang yang merupakan pelaku UMKM masih belum paham mengenai pembukuan, bahkan ada yang baru mendengar kata Akuntansi. Beberapa dari peserta yang merupakan pelaku 
UMKM bahkan tidak bisa membedakan antara modal usaha dan keuntungan (profit/laba usaha).

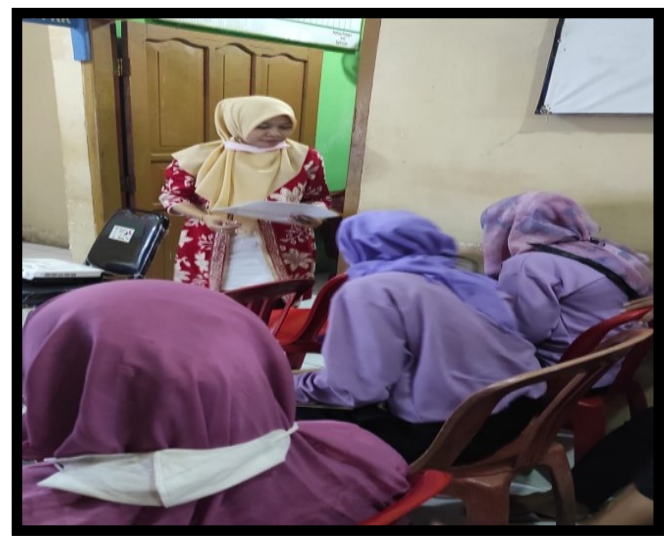

Gambar 3. Pembimbingan pada peserta

Materi yang disampaikan kepada peserta adalah mengenai pembukuan sederhana dan pengendalian intern. Peserta diajarkan bagaimana menyusun laporan keuangan sederhana. Adapun laporan yang mendasar yang perlu peserta pahami adalah laporan laba rugi, laporan perubahan ekuitas (modal), neraca serta laporan perubahan ekuitas. Beberapa laporan tersebut diperlihatkan melalui infocus dan peserta dibimbing dalam menyusun ketiga laporan keuangan tersebut pada kertas kerja. Peserta juga diberikan gambaran mengenai pelaksanaan pengendalian intern untuk mencegah terjadinya kerugian usaha. Selain itu, peserta juga diberikan tambahan informasi mengenai beberapa contoh aplikasi yang bisa digunakan melalui $\mathrm{hp}$ android untuk mengelola keuangan, misalnya saja Buku Warung dan Akuntansiku (Simamora, Safri \& Permatasari, 2021).

Kegiatan pengabdian kepada masyarakat tentang pelatihan pembukuan sederhana dan pengendalian intern pada UMKM diharapkan mampu meningkatkan keterampilan serta pengetahuan dalam mengembangkan UMKM serta meningkatkan omzet penjualan produk yang terbilang masih langka yaitu kripik tude.

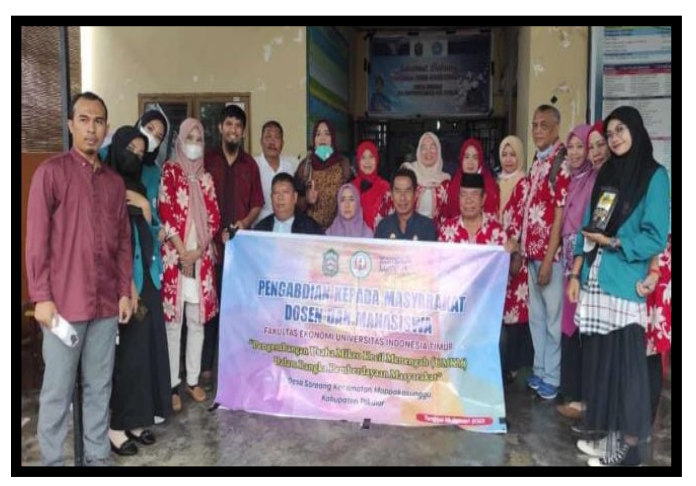

Gambar 4. Foto Bersama tim PKM dan Mahasiswa Bersama Kepala Desa Soreang

\section{SIMPULAN}

Berdasarkan pembahasan yang diuraikan, maka dapat ditarik kesimpulan yaitu masyarakat desa kelompok UMKM di Desa Soreang berpartisipasi dalam kegiatan PKM mendapatkan tambahan pengetahuan mengenai pembukuan sederhana dan sistem pengendalian intern, serta adanya tambahan keterampilan melalui pelatihan untuk mengembangkan UMKM dalam rangka pemberdayaan masyarakat di Desa Seroang.

\section{DAFTAR PUSTAKA}

Bachtiar, I. H., dan Nurfadila. (2019). Akuntansi Dasar Buku Pintar Untuk Pemula. Deepublish, Yogyakarta.

Cika, N. (2007). An International Perspective on Internal Controls in Small and Medium Enterprises. The Business Review, Cambridge, 8(1), 80-86. 
Jurdimas (Jurnal Pengabdian Kepada Masyarakat) Royal

Vol. 5 No. 1, Januari 2022, hlm. 105 - 110

Available online at https:/jurnal.stmikroyal.ac.id/index.php/jurdimas

Giyanti, I., Suparti, E., Sunardi, S., \& Sugiarti, S. (2021). Perbaikan Proses Produksi dan Peningkatan Pemasaran pada UKM Putri Timus Di Karanganyar. Jurdimas (Jurnal Pengabdian Kepada Masyarakat) Royal, 4(2), 127134.

Sari, C. T., \& Indriani, E. (2017). Pentingnya Pembukuan Sederhana Bagi Kelompok Umkm Kub Murakabi Desa Ngargoyoso. Wasana Nyata, 1(1), $17-21$.

https://doi.org/10.36587/wasanan yata.v1i1.189.
Simamora, S.C., Safri dan Permatasari, R.I. (2021). Pelatihan Aplikasi Keuangan Akuntansiku Bagi UMKM Binaan Wahana Visu Indonesia Jakarta. Aptekmas Jurnal Pengabdian Kepada Masyarakat, 4(3), 94-98.

Kemenkeu. (2021). Pemerintah Terus Perkuat UMKM Melalui Berbagai Bentuk Bantuan.

Wirawan, S., Djajadikerta, H., \& Setiawan, A. (2021). Penerapan Pengendalian Intern pada 13 UMKM di Bandung. Jurnal Administrasi Bisnis, 10(1), 3344.https://doi.org/10.14710/jab.v $10 \mathrm{i} 1.34009$ 